\title{
Isolation and characterization of the chemical constituents of Sonchus wightianus of Nepalese origin
}

\author{
Susan Joshi" and Tej Narayan Poudel \\ Central Department of Chemistry, Tribhuvan University, Kirtipur, Kathmandu, Nepal \\ E-mail: Susanjoshi68@gmail.com
}

\begin{abstract}
Phytochemical screening of Sonchus wightianus of Nepalese origin were carried out. Phytochemical screening showed the presence of fatty acids, triterpenes, sterols, polyphenols, emodins, quinones, glycosides, polyose and anthracenosides. Compounds $\beta$-sitosterol, $\beta$-sitosterol glycoside, 1 Hexacosanol and Hexadecanoic methyl ester were isolated.1-Hexacosanol and Hexadecanoic methyl ester are isolated for the first time from Sonchus wightianus.
\end{abstract}

Keywords: Phytochemical Screening, Sonchus wightianus, $\beta$-sitosterol, 1-Hexacosanol

\section{Introduction}

Sonchus is a perennial herb. The genus sonchus comprises 50 species distributed in Euroasia, around the Mediterrianean and tropical Africa. The word "Sonchus" comes from the Greek word meaning "hollow" which refers to hollow stems. Some of the important species of the genus are S. alpinus, S.arvensis, S. asper, S. macrocarpus, S. brachyotus, S.kirkii, S.wightinaus, S. hymanii, S. oleraceus, S. crataegifolium, S. tuberifer svent etc. ${ }^{1}$ Sonchus wightianus is distributed throughout Nepal at an altitude of 600-2,500m, Afganistian, Pakistan, India and Sri Lanka. ${ }^{2}$ It is a perennial herb with hollow stems and bitter milky juice. The alternate leaves are variable in size with prickly edges and pointed lobes. The flowers are bright yellow in color and blossom from June to September. It is commonly called as Sow Thistle and local name is Ban raayo or Dudhe. Numerious pharmacological activities on the genus sonchus have been reported. The leaves of the S. wightianus are used in earache by rural communities of India. ${ }^{3}$ The juice of S. alpinus is useful in deafness, gout, and old age. The roots of S.arvensis are used in cough, bronchitis, and asthma. The leaves are applied to swellings, while its latex is used for the treatment of eye diseases. ${ }^{4}$ The leaves and roots of the plant are used in indigestion and as a febrifuge, while its roots act as a vermifuge. Its stems are given as a tonic and sedative. ${ }^{4}$ In China, the extract of Sonchus species is used in appendicitis, tonsillitis and sore throat.

Despite the great significance of Sonchus species, not much work has been reported on the chemical and biological investigation of the Sonchus wightianus of Nepalese origin. Thus the present work is concentrated on the phytochemical screening of the aerial parts of Sonchus wightianus, isolation and identification of chemical constituents.

\section{Experimenal}

\section{General}

Melting points were determined by using melting point apparatus from Griffin and George Company Limited (UK). Column chromatography was performed using silica gel of mesh no. 60-120. For thin

\footnotetext{
* Corresponding author
} 
layer chromatography "Silica gel-G" was used. ${ }^{1} \mathrm{H}-\mathrm{NMR},{ }^{13} \mathrm{C}-\mathrm{NMR}$ spectra were recorded on UNITY plus-500 NMR spectrometer using TMS as internal standard and NMR spectra were recorded in chloroform $\left(\mathrm{CDCl}_{3}\right)$, DMSO, deuterated pyridine $\left(\mathrm{C}_{5} \mathrm{D}_{5} \mathrm{~N}\right)$. The Chemical shifts values were expressed in $\delta(\mathrm{ppm})$ value. EI-MS measurements were carried out on BioTOF II triple quadruple mass spectrophotometer.

\section{Collection of plant material}

The plant material chosen for the study was the aerial part of the Sonchus wightianus. The material was collected from Kavreplanchowk district of Nepal. The aerial part of the plant was air dried in shade and made powder.

\section{Phytochemical Screening}

The method employed for phytochemical screening was based on the procedure put forward by Prof. I. Ciulei. ${ }^{5}$ This method involves selective and successive extraction of the plant material by using solvent of increasing polarity. By using different specific reagents the presence of main groups of natural products is analyzed.

\section{Extraction and isolation of compounds}

The extraction of chemical constituents of plant material powder i.e. aerial part of Sonchus Wightianus $(500 \mathrm{gm}$ ) was carried out by using Soxhlet apparatus successively with petroleum ether, ethyl acetate and methanol.

The petroleum ether fraction $(10 \mathrm{~g})$ was subjected to column chromatography..The slurry was prepared by mixing petroleum ether fraction $(10 \mathrm{~g})$ with silica $(12.0 \mathrm{~g})$. The slurry was applied to the column and the column was eluted subsequently with the solvent of increasing polarity in the order of petroleum ether, chloroform, ethyl acetate and methanol. On eluting the column with petroleum ether$\mathrm{CHCl}_{3}$ (70:30), compound SW-1(1-hexacosanol) was obtained. On eluting the column with EtOAc$\mathrm{CHCl}_{3}$ (10:90), compound $\mathbf{S W - 2}$ ( $\beta$-Sitosterol) was obtained.

Since the methanolic extract of the plant contained a mixture of a large number of chemical constituents of wide-range polarities, it is fractionated by solvents of different polarities like Hexane, Chloroform, EtOAc and $\mathrm{MeOH}$ respectively using vacuum liquid chromatography.

The methanol fraction (8g) was subjected to column chromatography. The slurry was prepared by mixing methanol fraction $(8 \mathrm{~g})$ with silica $(11 \mathrm{~g})$. The slurry was applied to the column and the column was eluted subsequently with the solvent of increasing polarity in the order of petroleum ether, chloroform, ethyl acetate and methanol. On eluting the column with $75 \%$ of EtOAc in $\mathrm{CHCl}_{3}$, compound $\mathbf{S W - 3}$ ( $\boldsymbol{\beta}$ Sitosterol 3- $\boldsymbol{O}-\boldsymbol{\beta}$-D glycoside ) was obtained.

The chloroform fraction of methanol extract $(2 \mathrm{~g})$ was subjected to column chromatography..The slurry was prepared by mixing petroleum ether fraction $(2 \mathrm{~g})$ with silica $(3 \mathrm{~g})$. The slurry was applied to the column and the column was eluted subsequently with the solvent of increasing polarity in the order of petroleum ether, chloroform, and methanol. On eluting column with $10 \% \mathrm{CHCl}_{3}$ in pet.ether,compound SW-4 (Hexadecanoic methyl ester) was obtained.

\section{Result and Discussion}

\section{Phytochemical screening of S. wightianus}

By the procedure given by Prof.I.Ciulei,. the phytochemical screening of the plant s. wightianus was performed. The result are presented as below. 
Photochemical screening of various extracts

\begin{tabular}{|l|l|c|c|c|}
\hline S.N. & Group of the compounds & Pet. Ether Extract & EtOAc Extract & MeOH extract \\
\hline 1 & Volatile oil & - & - & - \\
\hline 2 & Basic alkaloids & - & - & - \\
\hline 3 & Carotinoids & - & - & + \\
\hline 4 & Terpenes/sterol & + & + & - \\
\hline 5 & Fatty acid & + & + & - \\
\hline 6 & Cumarins & - & - & - \\
\hline 7 & Flavone aglycones & - & - & + \\
\hline 8 & Emodins & + & + & + \\
\hline 9 & Quinones & + & + & + \\
\hline 10 & Polyphenols & - & + & + \\
\hline 11 & Glycosides & - & + & + \\
\hline 12 & Saponins & & & + \\
\hline 13 & Anthrocenocides & & & + \\
\hline
\end{tabular}

$+=$ Presence, $-=$ Absence

\section{Analysis and Identification of Isolated chemical constituents}

Compound: SW-1 (1-Hexacosanol)

Compound SW-1, white amorphous substance was found which was soluble in chloroform. The melting point of this compound was found to be $72^{\circ} \mathrm{c}$. It was found to single spot on TLC with Rf value 0.46 in $75 \% \mathrm{CHCl}_{3} /$ Pet.ether.

In ${ }^{1} \mathrm{H}-\mathrm{NMR}$ spectrum triplet at $\delta 0.90$ accounted for one methyl group. The big multiplet at $\delta 1.25$ accounted for hydrogens of $-\mathrm{CH}_{2}$ units. The triplet at $\delta 3.65$ account for the protons of $-\mathrm{CH}_{2}$ unit attached with electronegative oxygen atom.

${ }^{13} \mathrm{C}-\mathrm{NMR}$ showed the presence of 7 types of carbon atoms which have chemical shift at $\delta 63.01$, $32.90,32.04,29.694,25.83,21.3$ and 13.8 were accounted for carbon numbers 1, 2, 24, 4 to 23, 3, 25, 26 respectively. 
On the basis of all these spectral analysis, the compound was identified as long chain fatty alcohol, 1Hexacosanol ${ }^{6}$ From our best knowledge of literature survey, this compound is isolated for the first time from Sonchus wightianus.

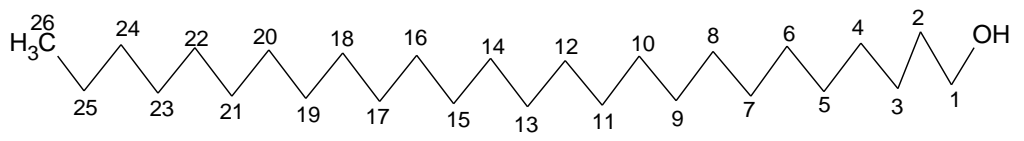

\section{1-Hexacosanol}

\section{Compound: SW-2 ( $\beta$-Sitosterol)}

White amorphous solid was found which was soluble in chloroform, ethylacetate and methanol. The melting point of this compound was found to be $130^{\circ} \mathrm{C}$. The compound had $\mathrm{R}_{\mathrm{f}}$ value of 0.43 in $20 \%$ ethyl acetate in hexane.By Co-TLC with authentic sample, it was found that the compound have the same $\mathrm{R}_{\mathrm{f}}$ value of that $\beta$-Sitosterol. The mass spectrum showed $\mathrm{M}^{+}$at $\mathrm{m} / \mathrm{z}$ at 414 corresponding to the molecular formula $\left(\mathrm{C}_{29} \mathrm{H}_{50} \mathrm{O}\right)$.

The IR spectrum showed presence of $-\mathrm{OH}$ group $\left(3434 \mathrm{~cm}^{-1}\right)$. The absorption bands at $2961 \mathrm{~cm}^{-1}$ and $1383 \mathrm{~cm}^{-1}$ were due to the $\mathrm{C}-\mathrm{H}$ stretching and bending respectively. A peak at $1063 \mathrm{~cm}^{-1}$ showed the presence of $\mathrm{C}-\mathrm{O}$ stretching.

The ${ }^{1} \mathrm{H}-\mathrm{NMR}$ spectrum showed two singlets at $\delta 1.00$ and at 0.67 are methyl group of C-19 and C-18 respectively. The doublets at $\delta 0.92(\mathrm{~d}, \mathrm{~J}=6.1 \mathrm{~Hz}) ; 0.81(\mathrm{~d}, \mathrm{~J}=6.9 \mathrm{~Hz}) ; 0.83(\mathrm{~d}, \mathrm{~J}=6.9 \mathrm{~Hz})$ and $0.84(\mathrm{t}, \mathrm{J}$ $=7.3 \mathrm{~Hz})$ were accounted for methyl group at C-21, C-25, C-27 and C-29. A doublet at $\delta 5.35(\mathrm{~d}, \mathrm{~J}=20.5$ $\mathrm{Hz}$ ) in ${ }^{1} \mathrm{H}-\mathrm{NMR}$ can be accounted for an olefenic proton at C-6. Other multiplet at $\delta 3.52$ (ddd, J = 13.2, $16.0,16.0 \mathrm{~Hz}$ ) equivalent to a singlet proton was assigned for the proton of $\mathrm{C}-3$. The low field signal may be due to the attachment of $\beta-\mathrm{OH}$ group at $\mathrm{C}-3$ carbon. Thus, the assignment of hydroxyl group at $\mathrm{C}-3$ and the double bond at $\mathrm{C}-5$ were assigned accordingly. Three multiplets equivalent to two protons each appeared at $\delta 1.83,2.00$ and 2.27 were assigned for $3-\mathrm{CH}_{2}$ groups. The remaining protons have appeared as multiplets at $\delta 1.05-1.65$.

The respective fragments were assigned by the mass spectrum with $\mathrm{m} / \mathrm{z} 399,396,381,329,273$, and 255 . From all these spectral analysis, the compound was $\beta$-Sitosterol, previously isolated from large number of Nepalese plant species. ${ }^{7}$

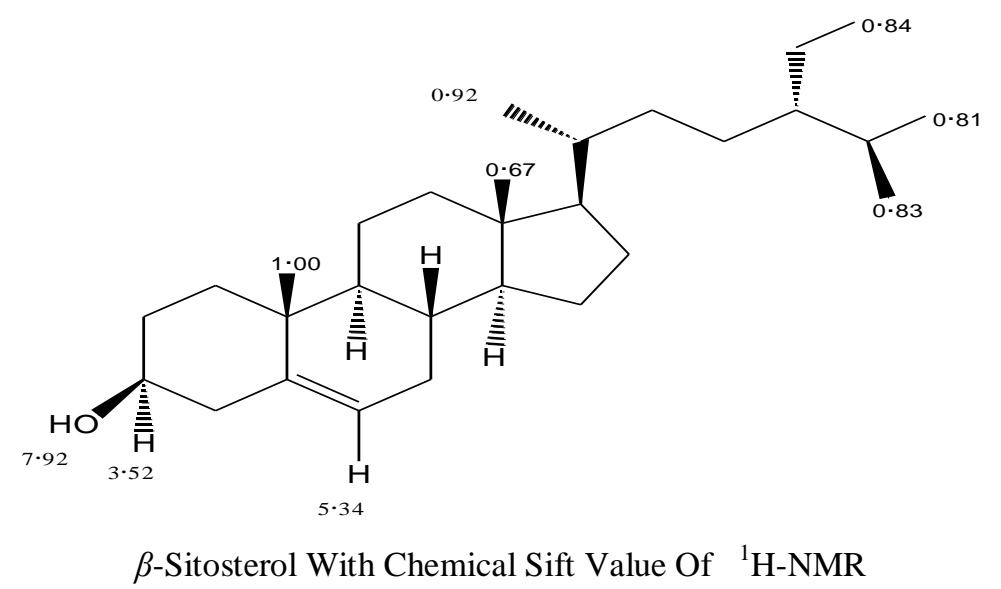




\section{Compound: SW-3 ( $\beta$-Sitosterol 3-O- $\beta-D$ glycoside )}

Compound SW-3 melting point above $284^{\circ} \mathrm{C}$ with $\mathrm{R}_{\mathrm{f}}$ value 0.66 (1:9, methanol: chloroform) was white crystalline compound. ${ }^{1} \mathrm{H}$ - NMR spectrum pattern was similar to that of $\beta$-sitosterol with some additional peaks relating to a carbohydrate moiety. The multiplet at $\delta 4.27$ was assigned for the proton of $\mathrm{C}-3$. Its deshielding may be due to attachment of $\beta$ - $O$-glucosyl moiety at $\mathrm{C}-3$ carbon. The proton signals at $\delta 3.96,4.03,4.27,4.52,4.53$, and 5.02 in the deshielded region were assigned for respective Gly- 5, Gly-2, G-3, Gly-4, Gly-6, and Gly-1 protons of glucosyl moiety. ${ }^{13} \mathrm{C}$-NMR was also similar to $\beta$-sitosterol with additional six peaks confirming the glucose ring. It showed the presence of 35 carbons of which chemical shift at $\delta 102.60,75.33,78.4,71.74,78.16$, and 62.88 were assigned for carbon atoms of glucosyl moiety.

Both ${ }^{1} \mathrm{H}-\mathrm{NMR}$ and ${ }^{13} \mathrm{C}-\mathrm{NMR}$ values of glucosyl moiety were confirmed by comparing with authentic values of glucose. Further the above structural arrangement was confirmed by two-dimensional spectroscopy $\left({ }^{1} \mathrm{H}-{ }^{1} \mathrm{H}\right.$ COSY, HMBC and HMQC). They gave correlations of protons and carbon atoms. They correlated the presence of glycosyl moiety at 3 position of steroid framework All the spectral values obtained from ${ }^{13} \mathrm{C}-\mathrm{NMR},{ }^{1} \mathrm{H}-\mathrm{NMR}, \mathrm{HMBC}$ and HMQC identified the compound as $\beta$ - Sitosterol glycoside. ${ }^{8}$

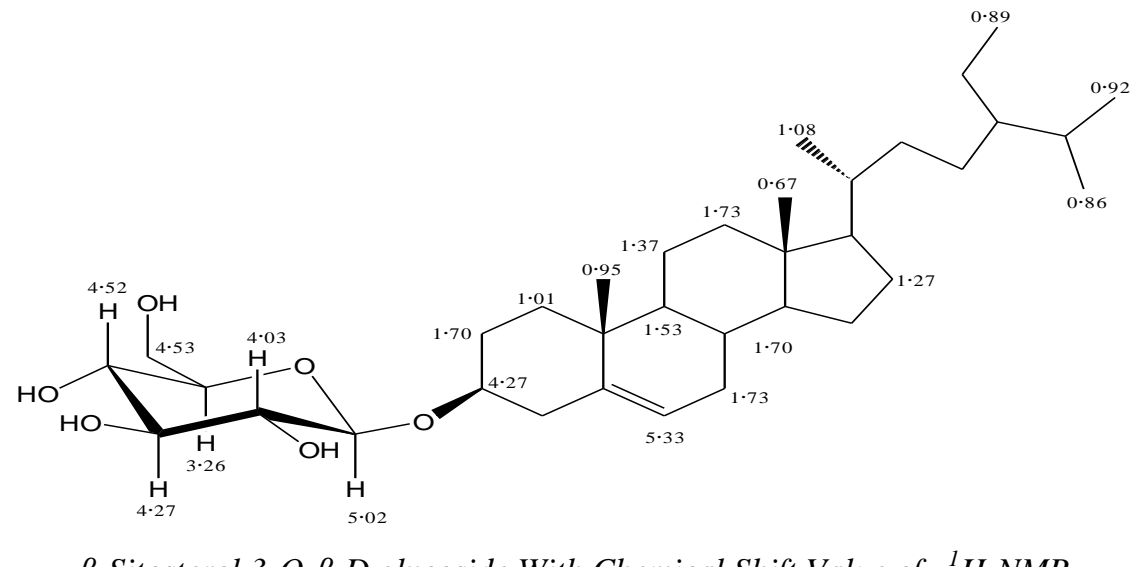

$\beta$-Sitosterol 3-O- $\beta$-D glycoside With Chemical Shift Value of ${ }^{1} H$-NMR

\section{Compound: SW-4 (Hexadecanoic methyl ester)}

Compound SW-4, white amorphous compound was found to single spot on TLC with Rf value 0.43 in $15 \% \mathrm{CHCl}_{3} /$ Pet.ether.The compound had melting point $74^{\circ} \mathrm{C}$. The mass spectrum showed $\mathrm{M}^{+}$at 270.4 corresponding to the molecular formula $\mathrm{C}_{17} \mathrm{H}_{34} \mathrm{O}_{2}$.

In ${ }^{1} \mathrm{H}-\mathrm{NMR}$ spectrum triplet at $\delta 0.90(\mathrm{~J}=13.1,3 \mathrm{H})$ accounted for one methyl group. The singlet at $\delta$ $3.64(\mathrm{~J}=3.52,3 \mathrm{H})$ accounted for methyl group of $\left(-\mathrm{OCH}_{3}\right)$ unit. The multiplet at $\delta 2.29(\mathrm{~J}=17,2 \mathrm{H})$ were due to the hydrogens of $-\mathrm{CH}_{2}$ attached to $\mathrm{C}=\mathrm{O}$. The broad multiplet at $\delta$ value 1.19 to 1.33 was due to the $13-\mathrm{CH}_{2}$ groups $(26 \mathrm{H})$.

Further the structure was confirmed by mass spectrum analysis. The molecular ion at $\mathrm{m} / \mathrm{z} 270$ is clearly seen. The most characteristic and base peak is $\mathrm{m} / \mathrm{z} 74$ resulting the McLafferty rearrangement.There is no prominent peak at $[\mathrm{M}-\mathrm{OH}]$ and $[\mathrm{M}-\mathrm{COOH}]$. These represent there is no short chain.Beside the McLafferty rearrangement peak there is series of hydrocarbon clusters at interval of 14 mass units.

On the basis of all these spectral analysis, the compound was identified as Hexa decanoic methyl ester. ${ }^{9}$ From our best knowledge, this compound is isolated for the first time from Sonchus wightianus. 


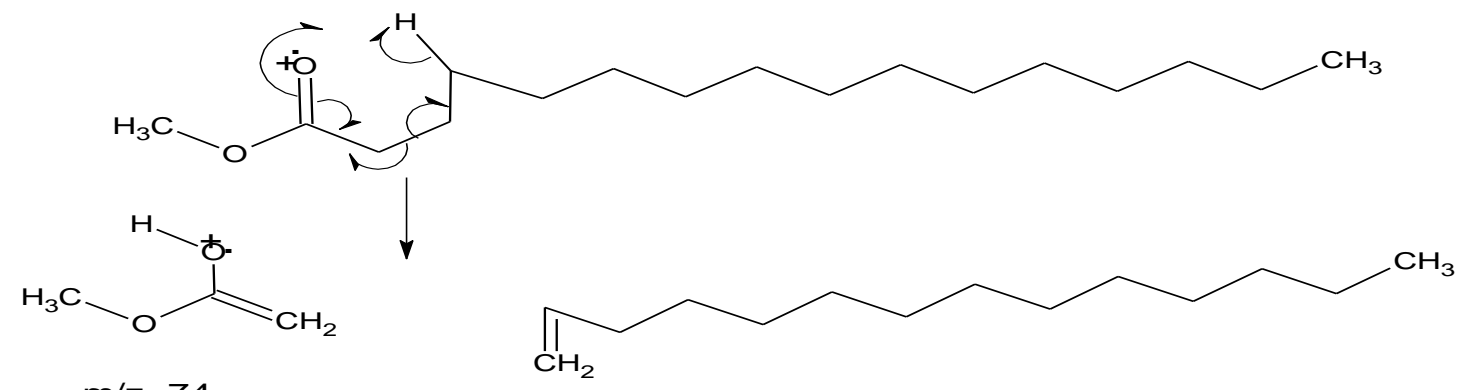

The mass fragmentation patterns of SW-4

\section{Conclusions}

Phytochemical screening of different extracts of Sonchus wightianus showed the presence of fatty acids, triterpenes, sterols, polyphenols, emodins, quinones, glycosides, polyose and anthracenosides. Compounds $\beta$-sitosterol and 1-Hexacosanol were isolated from petroleum ether extract of the plant and identified. Similarly, compounds $\beta$-sitosterol glycoside and Hexadecanoic methyl ester were isolated from methanol extract and identified.

\section{References}

1. Hooker,J.D., "Flora of British India", Reeve and co;London,1982, 3, 414.

2. "National Action plan for Biodiversity", Ministry of Environment and forests, Government of India, New Delhi, 1997, p207.

3. "Flowering plants of Nepal",HMG,Ministry of forests and soil conservation,Department of plant Resources,Kathmandu, 2001, p.336.

4. Ambasta,S.P., "The useful plants of India" National Institute of science communication, council of scientific and industrial Research, New Delhi, 1992, p.584.

5. Ciulei, I. In., "Methods for Studying Drugs"

6. Moreira, R.F.A, Trugo, L.C. Pietroluongo, M.Demaria, C.A.B., "Journal of Agricultural and Food Chemistry”, 2002, 50, 7616-7621(Eng.), American Chemical Society.

7. Heble, M. R.; Narayanaswami,S., and Chanda, M.S., Science,1967, 161, 1145.

8. Monako, P. and Previtera, L.," Journal of Natural Product”, 1984, 47, 1145.

9. Mahato, S. B., Sahu N. P., Narayanswami A. and Chakraverti R.N., "Journal of Indian chemical society", 1975, 3, 626. 